\title{
A Cadaveric Study of Different Angles of Scapula and their Role in Kinesiometrics and Muscle Morphology
}

\author{
Ritika Sharma, ${ }^{1}$ Rajan Kumar Singla, ${ }^{2}$ Jagdev Singh Kullar, ${ }^{2}$ Rajan Sharma, ${ }^{3}$ Tripta Sharma $^{4}$ \\ 'Department of Anatomy, Chintpurni Medical College, Pathankot, ${ }^{2}$ Department of Anatomy, Government Medical College, \\ Amritsar, ${ }^{3}$ Department of Orthopaedics, Sri Guru Ram Das Institute of Medical Sciences and Research, Vallah, Sri Amritsar, \\ ${ }^{4}$ Department of Anatomy, Punjab Institute of Medical Sciences and Research, Jalandhar, Punjab, India.
}

Introduction: The bipedal gait and consequential freedom of the upper limb in human beings has made the movements of the shoulder joint a subject of extensive investigations. The scapular angles provide the base and leverage to various muscles and have been correlated with the different movements of the shoulder joint.

Methods: In the present study, different angles of scapula namely superior, inferior, lateral, medial, acromial and coracoid angles were measured in the North Indian population. The study was conducted on 100 scapulas ( $R: L=50: 50)$ obtained from Department of Anatomy, Government Medical College, Amritsar. For measuring the angles, centimetre scales and protractor were used.

Results: The mean value of superior angle was observed to be $100.83^{\circ}\left(\mathrm{R}=100.32^{0}: \mathrm{L}=101.34^{\circ}\right)$; inferior angle was $63.62^{\circ}\left(\mathrm{R}=68.1^{0}: \mathrm{L}=59.14^{\circ}\right)$; lateral angle was $61.72^{\circ}\left(\mathrm{R}=65.9^{0}: \mathrm{L}=57.54^{0}\right)$; medial angle was $147.64^{\circ}\left(\mathrm{R}=151.32^{\circ}: \mathrm{L}=143.96^{\circ}\right)$; acromial angle was $106.47^{\circ}\left(\mathrm{R}=107.68^{\circ}: \mathrm{L}=105.26^{\circ}\right)$ and coracoid angle was $83.3^{\circ}\left(\mathrm{R}=84.24^{0}: \mathrm{L}=82.02^{\circ}\right)$.

Conclusions: It was observed that all angles were higher in the right sided bones except superior angle. Also a wide range was seen in all the angles.

Keywords: acromial; coracoid; inferior; medial; superior.

\section{INTRODUCTION}

The relationship between the bony anatomy and stability of a joint is important in the understanding of its biomechanicalbehaviour during loading and movement, in terms of the forces transmitted across the joint and of its kinematics. This is particularly important in the shoulder joint where there is discrepancy between the shape of the glenoid fossa and that of the humeral head. ${ }^{1}$

Nevertheless, extensive investigations have been done on the shoulder joint and shoulder girdle owing to the acquisition of bipedal gait and consequential freedom of movement of the upper limb in human beings. The role of the scapula has been studied from different viewpoints and its shape, size and movements have been correlated with the movements of the shoulder joint and the shoulder girdle. ${ }^{2}$ The scapula bears various angles namely superior, inferior, lateral, medial, acromial and coracoid angle. The superomedial scapular angle,

Correspondence: Dr. Ritika Mahajan, Department of Anatomy, Chintpurni Medical College, Pathankot, Punjab, India. Email: sharmaritika29@ymail.com, Phone: 09501400897. 
which is difficult to measure, has only been described in clearly pathological cases. ${ }^{3}$

\section{METHODS}

The material for the present study comprised of 100 adult scapulae of unknown sex and age, obtained from department of Anatomy, Government Medical College, Amritsar, Punjab, India. These were labelled from 1-100 with suffix $\mathrm{R}$ (right) or $\mathrm{L}$ (left). Of the 100 bones, 50 were of the right side and 50 were of the left side. All the bones were free from any physical deformity or abrasion and were complete in all respects. The various angles were measured with the help of scales and protractor. Each angle was defined as follows :

1. Superomedial/Superior angle: It was measured as the angle where the superior border meets the medial or the vertebral border of the scapula. ${ }^{2}$ For measuring this angle, one scale was placed along the superior border of the scapula and another scale was placed along the medial border on the supraspinous line and angle between both was measured with the help of protractor (Figure1 and 2).

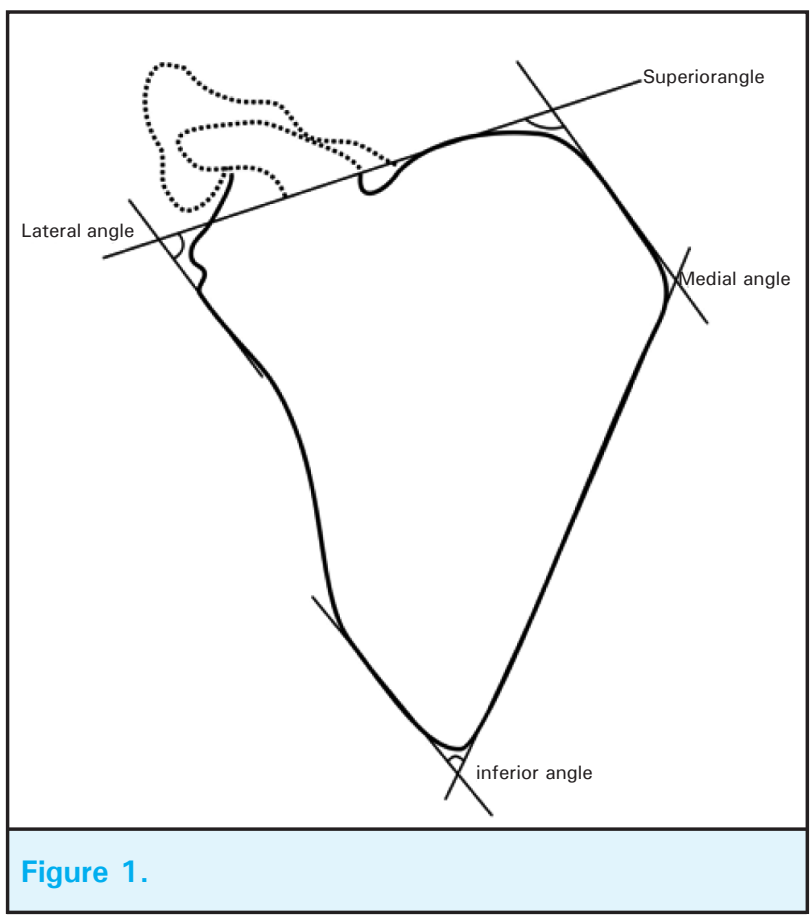

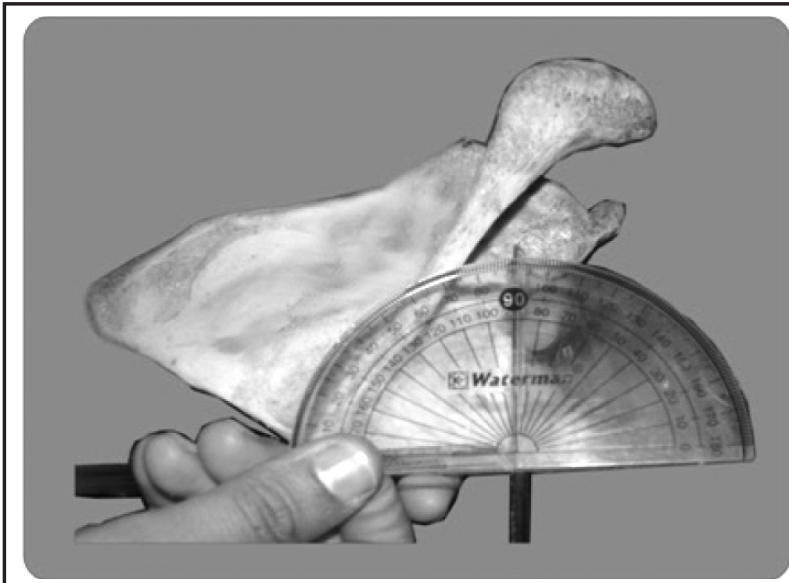

Figure 2. Measurement of Superior Angle.

2. Inferior angle: It was measured as the angle where the medial or the vertebral border of the scapula meets the lateral or the axillary border. ${ }^{2}$ For measuring this angle the scale was placed along the medial border of the scapula and another scale was placed along the lateral border of the scapula. Then angle between the two scales was measured with the help of the protractor (Figure 1 and 3).

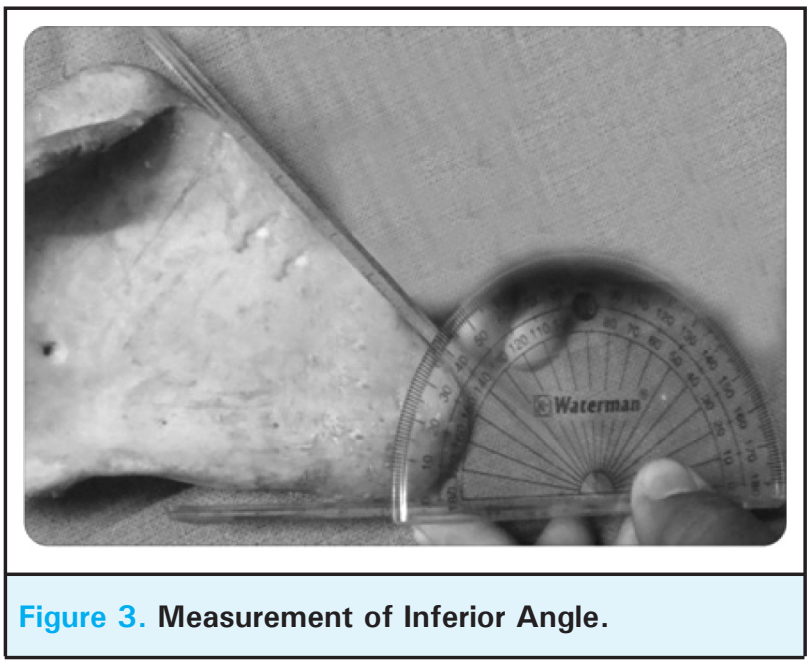

3. Lateral angle: It was measured as an open angle where the superior and the lateral or the axillary borders are wedged by the glenoid fossa. ${ }^{2}$ For measuring this angle a scale was placed along the lateral border touching the infraglenoid tubercle and another scale was placed along the superior border and angle between both was measured with the help of protractor $^{2}$ (Figure 1 and 4). 


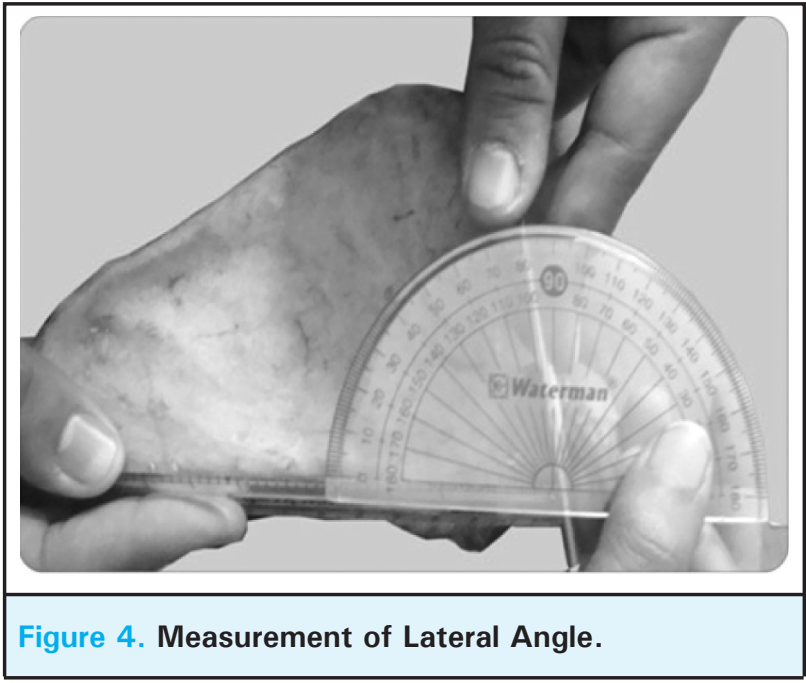

4. Medial angle:It was measured as the angulation of the bone formed at the medial end of the anterior border of the crest of the spine of the scapula where the plate like body of the bone is bent between the medial borders of the supraspinous and the infraspinous fossae. ${ }^{2}$ For measuring this angle a scale was placed along the supraspinous line and another scale was placed along the infraspinous line and an angle between both was measured with the help of protractor (Figure 1 and5).

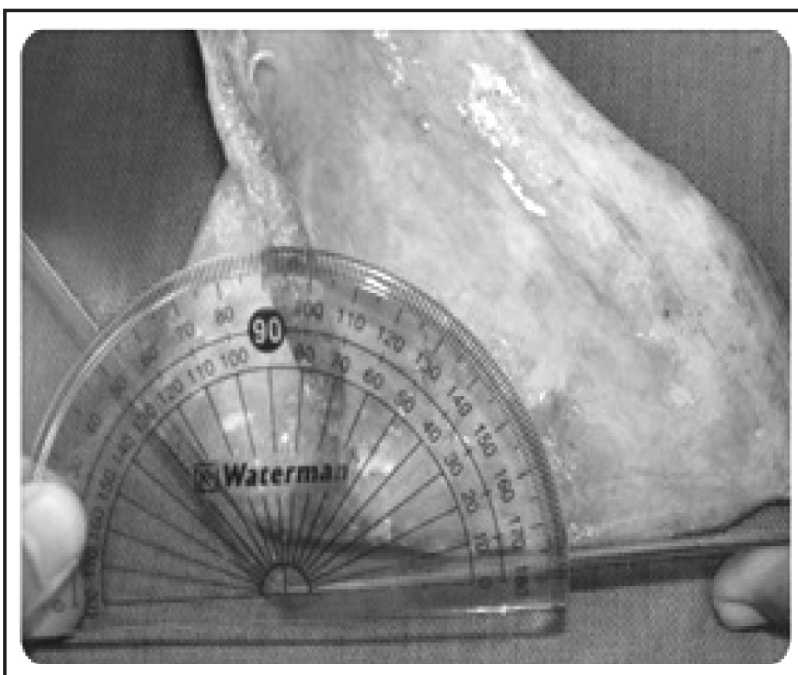

Figure 5. Measurement of medial angle.

5. Acromion angle: It was measured as the angle where the lower border of the crest of the spine becomes continuous with the lateral border of the acromion process. For measuring this angle, a scale was placed along the lateral border of the acromion and other scale was placed along the inferior border of the acromion and the angle between both was measured with the help of protractor. ${ }^{2}$ (Figure 6 ).

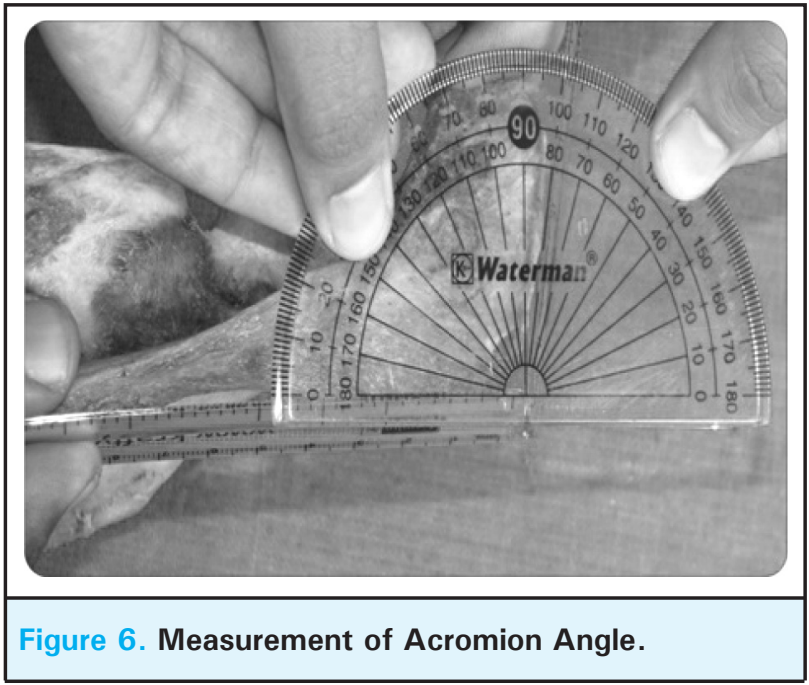

6. Coracoid angle: It was measured with the help of protractor as the angle formed where the root of the coracoid process is bent sharply so as to project forward and slightly laterally. ${ }^{2}$ For measuring this angle a scale was kept along the lateral border of the coracoid process and another scale was kept along the root of the coracoid process. The angle between the two scales was measured with the help of a protractor (Figure 7).

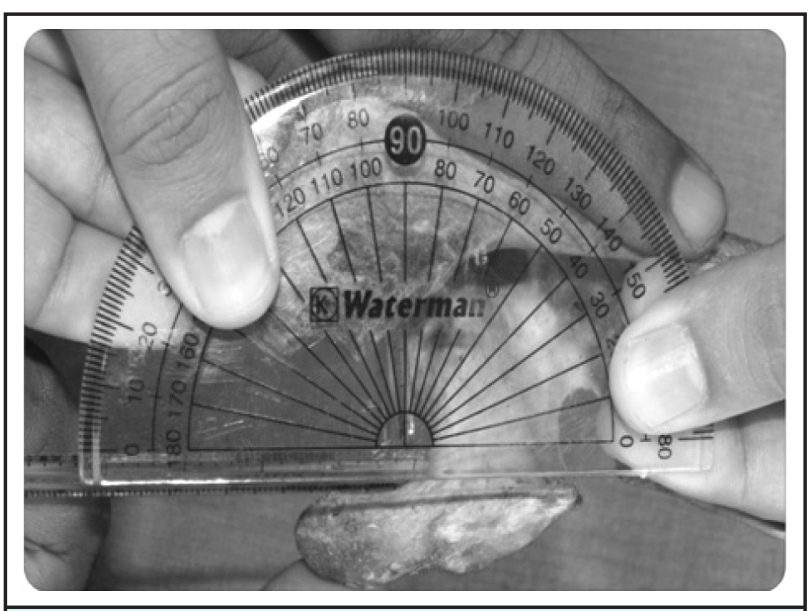

Figure 7. Measurement of Coracoid Angle.

\section{RESULTS}

All the values observed were tabulated and the mean value and range were calculated for left and right side (Table 1). 
Table 1. Showing comparison of different angles of scapula with earlier studies.

\begin{tabular}{|c|c|c|c|c|c|c|c|c|c|c|}
\hline \multirow[t]{3}{*}{ Angle } & \multicolumn{4}{|c|}{ Present Study } & \multicolumn{2}{|l|}{ Solanki } & \multicolumn{2}{|c|}{$\begin{array}{l}\text { Piyawinijwong et } \\
\mathrm{al}^{4}\end{array}$} & \multicolumn{2}{|c|}{ Coskun et al $^{5}$} \\
\hline & \multicolumn{2}{|l|}{ Mean } & \multicolumn{2}{|l|}{ Range } & \multirow[t]{2}{*}{ Mean } & \multirow[t]{2}{*}{ Range } & \multirow[t]{2}{*}{ Mean } & \multirow[t]{2}{*}{ Range } & \multirow[t]{2}{*}{ Mean } & \multirow[t]{2}{*}{ Range } \\
\hline & Right & Left & Right & Left & & & & & & \\
\hline Superior & $100.32^{\circ}$ & $101.34^{\circ}$ & $\begin{array}{l}86^{\circ}- \\
120^{\circ}\end{array}$ & $\begin{array}{l}80^{\circ} \\
120^{\circ}\end{array}$ & $99.84^{\circ}$ & $\begin{array}{l}60^{0}- \\
133^{0}\end{array}$ & $84.92^{\circ}$ & $53^{\circ}-112^{0}$ & $124.40^{\circ}$ & \\
\hline Inferior & $68.1^{\circ}$ & $59.14^{0}$ & $\begin{array}{l}47^{0}- \\
90^{\circ}\end{array}$ & $\begin{array}{l}42^{\circ} \\
79^{\circ}\end{array}$ & $68.08^{\circ}$ & $41^{0}-94^{0}$ & $39.42^{\circ}$ & $30^{\circ}-42^{0}$ & & \\
\hline Lateral & $65.9^{\circ}$ & $57.54^{\circ}$ & $\begin{array}{l}41^{0}- \\
88^{\circ}\end{array}$ & $\begin{array}{l}30^{\circ} \\
80^{\circ}\end{array}$ & $76.44^{\circ}$ & $\begin{array}{l}42^{0}- \\
123^{0}\end{array}$ & & & & \\
\hline Medial & $151.3^{\circ}$ & $143.96^{\circ}$ & $\begin{array}{l}133^{\circ} \\
173^{\circ}\end{array}$ & $\begin{array}{l}126^{\circ} \\
170^{\circ}\end{array}$ & $142.20^{\circ}$ & $\begin{array}{l}115^{\circ} \\
163^{\circ}\end{array}$ & & & & \\
\hline Acromial & $107.68^{\circ}$ & $105.26^{\circ}$ & $\begin{array}{l}90^{0}- \\
135^{\circ}\end{array}$ & $\begin{array}{l}90^{\circ}- \\
138^{\circ}\end{array}$ & $135.30^{\circ}$ & $\begin{array}{l}99^{0}- \\
158^{\circ}\end{array}$ & & & $124.40^{\circ}$ & $\begin{array}{r}112^{\circ} \\
136^{\circ}\end{array}$ \\
\hline Coracoid & $84.24^{0}$ & $82.02^{\circ}$ & $\begin{array}{l}56^{\circ}- \\
96^{\circ}\end{array}$ & $\begin{array}{l}52^{\circ}- \\
100^{\circ}\end{array}$ & $94.30^{\circ}$ & $\begin{array}{l}43^{\circ}- \\
145^{\circ}\end{array}$ & & & $124.8^{\circ}$ & \\
\hline
\end{tabular}

\section{DISCUSSION}

The bipedal gait and consequential freedom of the upper limb in human beings has made the movements of the shoulder joint a subject of extensive investigations. ${ }^{2}$ Bardin ${ }^{4}$ studied the development of scapula and observed that the general triangular form emerges during development even before any significant force is applied to it. Inman et $\mathrm{al}^{5}$ threw a flood of light on evolution of scapula from primates to human beings, morphology of various muscles in relation to movements of the shoulder, electromyographicbehaviour of these muscles and mechanics of the movements. Codman ${ }^{6}$ and Kelley ${ }^{7}$ touched the kinesiological aspects of scapula and its movements. However, all of them except Inman et $\mathrm{al}^{5}$ ignored the role of different angles of the scapula in providing the base and leverage to various muscles and thus determining their effective roles in different movements.

Codman ${ }^{6}$ named the complex mechanism of shoulder joint as "Scapulohumeral rhythm" which includes sternoclavicular joint, acromioclavicular joint, scapulothoracic and glenohumeral joints. Inman et $\mathrm{al}^{5}$ are of the view that to establish equilibrium at glenohumeral joint in any of its positions, three forces are required viz. weight of the limb acting at its centre of gravity, the abducting musculature and pressure and friction of the head of the humerus at the glenoid cavity. They further believed that various skeletal changes in scapula and the morphological changes in the muscles have established the necessary components of forcecouple. So the role of different angles of scapula should be viewed in the light of above mentioned observations so that a proper and useful function is assigned to them.

1. Superior Angle: Its mean value and range on the two sides as observed in the present study is compared with the earlier studies in (Table 1). None of the earlier workers have measured it separately on the two sided bones. As evident from the table, our values are in consonance with Solanki ${ }^{2}$ who measured it in Indian population, but more as compared with Piyawinijwong et al ${ }^{8}$ who measured it in Thai population and less as compared with Coskun et $\mathrm{al}^{9}$ who measured it in Turkish population. Thus, it indicates a strong racial and regional influence on this angle.

Role of superior angle in scapular kinesiometrics and muscle morphology. Inman et $\mathrm{al}^{5}$ are of the opinion that the superior angle provides the base for the upper force-couple for the elevation and the rotation of the scapula. On studying the phylogeny, it is observed that serratus anterior and the levator scapulaewere a continuous sheet of muscle in primates which has undergone a morphological change by separating into two muscles. The concentrated insertion of the serratus anterior (upper part) and the levator scapulae along with the upper trapezius form the upper component of the force-couple for the rotation of the scapula. The postural function of this group is evidenced by the fact that these muscles exhibit an action current potential while the arm is at rest during electromyography. With the elevation of the arm in flexion and abduction, the amplitude of their action current potential rises in linear form reaching its maximum in the over-head abduction. Scheving and Pauly. ${ }^{10}$ maintain that the upper part of 
the serratus anterior is active in all the movements of the arm

2. Inferior angle (Table 1): It compares the mean value and range on the two sides as observed in the present study with the earlier studies. Our values are again in consonance with Solanki ${ }^{2}$ but almost 1.5 times as compared with Piyawinijwonget $\mathrm{al}^{4}$ again showing a racial influence. Even in the present study it was seen to be quite more $\left(68.1^{\circ}\right)$ in right sided bones as compared with left sided bones $\left(59.1^{\circ}\right)$. It is an important observation not mentioned by earlier authors.

Role of inferior angle in scapular kinesiometrics and muscle morphology

This angle along with the infraspinous fossa has undergone drastic changes during the evolution and these provide -

(i) The lower component of the force-couple for the rotation of the scapula and

(ii) The depressor action for the humerus.

The former is accomplished by the lower concentrated insertion of the five lowest digitations of the serratus anterior acting along with the lower trapezius. Inman et $\mathrm{al}^{5}$ believed that the $7^{\text {th }}$ and the $8^{\text {th }}$ digitations of the serratus anterior act predominantly in flexion while Scheving and Pauly. ${ }^{10}$ It support the view that they are active in all movements of the shoulder. The second factor i.e. depressor action for humerus is contributed by the independent existence of the teres minor and consequent migration of the deltoid to the humerus and therefore the combined action of the infraspinatus, the teres minor and the subscapularis acts for the depression of the humerus. This depression of the humerus is checked by a locking mechanism on the slope of the glenoid cavity which tightens the capsule superior to the joint and which may be reinforced by the activity of the supraspinatus. ${ }^{11}$

3. Lateral angle (Table 1): It compares the values of this angle on the two sides as observed in the present studywith the only earlier study by Solanki ${ }^{2}$ As evident from the table our values are more both on right and left sides when compared with the mean value provided by him (Solanki $^{2}$ did not differentiate between the two sides). This shows the regional impact on the value of this angle. When compared between the two sides, as in the case of inferior angle, this angle was also more on the right side.
Role of lateral angle in scapular kinesiometrics and muscle morphology

This angle is occupied by the glenoid fossa and the pressure and the friction of humeral head against glenoid fossa is a force of considerable size. Electromyographic studies have shown that the summit of the curve reaches at $90^{\circ}$ elevation where it represents 10.2 times, the weight of the extremity. ${ }^{5}$ Three forces are acting on this angle during any movement of the gleno-humeral joint to maintain the equilibrium (vide supra). These forces acting at the glenoid shape the angle to provide the optimum movements.

4. Medial angle: It was also found more on the right side as compared with the left side in the present study (Table 1). When compared with the only earlier study by Solanki ${ }^{2}$ the values of left sided bones were comparable but right sided bones distinctly depict a higher value of this angle.

Role of medial angle in scapular kinesiometrics and muscle morphology

Not much material related to this angle could be traced in the accessible literature. However, Inman et $\mathrm{al}^{5}$ are of the opinion that this angle could have developed as a consequence of uneven skeletal changes in the scapula, increase of the scapular index, the relative static shape of the supraspinous fossa, the reduction of the mass and size of the supraspinatous along with the bulk of the subscapularis which has relatively decreased in muscle mass but has increased its fasciculi as the infraspinous fossa increased. ${ }^{5}$

5. Acromial angle: It was found to be less in the present study as compared with the earlier studies by Solanki ${ }^{2}$ and Coskun et $\mathrm{al}^{9}$ as shown in (Table 1). When compared between the two sides, it was slightly more on the right side in the present study.

Role of acromial angle in scapular kinesiometrics and muscle morphology

This angle may be better understood in terms of two muscles attached to it- the deltoid and the trapezius and their role in the scapula-humeral rhythm. The considerable development of the acromion compared to the lower primates, has provided the increased leverage to the deltoid which has detached its attachments from the inferior angle and has increased in mass and size to play its role in the movements of the free upper limb. Electromyographic studies ${ }^{5,10,12}$ have shown that with the pull of the deltoid, the essential force-couple is established for the elevation of the shoulder, the force reaching maximum at $60^{\circ}$ and reaching zero at $135^{\circ}$. It may be noted that it is in contrast with the abduction 
movement at the acromioclavicular joint where the activity is limited below $30^{\circ}$ and beyond $135^{\circ}$. The role of the deltoid at the lateral angle has already been discussed.

The other muscle influenced by the enlargement of the acromion is the trapezius whose role in the formation of the force-couple has already been given in superior angle. Myographic studies suggest that in the resting position this muscle is only supportive. ${ }^{12}$ Later on assumes the rotator role. It may be safely assumed that the formation of the acromial angle is compensatory for the developing deficiency in the intermediate part of the muscle lying opposite the spine of the scapula. ${ }^{2}$

6. Coracoid angle: It was also found to be less in the present study as compared with the earlier studies by Solanki ${ }^{2}$ and Coskun et $\mathrm{al}^{9}$ (Table 1). When compared between the two sides, it was also slightly more on the right side.

Role of coracoid angle in scapular kinesiometrics and muscle morphology

The importance of the coracoids angle can be attributed to two factors-

(i) The separation of the pectoralis minor as a separate muscle from the pectoralis major and its consequent insertion in the coracoid process instead of the humerus as in the lower mammals. ${ }^{5}$ As the acromion process increases, this transference of the insertion of the pectoralis minor helps in the formation of the subdeltoid bursa which is first seen in the chimpanzee among the primates.

(ii) The short head of the biceps brachii which is absent in the primitive mammals.

The role of the pectoralis minor in depressing the shoulder and the short head of the biceps acting on the humerus can be taken yet another contribution in the mechanics of the shoulder movements of a free upper limb.

Thus all the angles of scapula except the superior angle were more on the right side as compared with the left side. Their mean values were comparable to studies by Solanki ${ }^{2}$ with some differences but quite different from those of Piyawinijwonget $\mathrm{al}^{8}$ and Coskun et $\mathrm{al}^{9}$ which were done in Thai and Turkish populations respectively. It may be attributed to the racial and regional factors. Even in the present study, a wide range of all the angles was observed which may be probably because of individual habits of posture, activity, general development of the muscles and bone and last but not the least, the sex.

\section{CONCLUSIONS}

To summarize, the present study provides a base line data of different scapular angles on the two sides. It also defines their role in free movement of the shoulder joint. These findings could be of great value in the further exploration of roles of the subject.

\section{REFERENCES}

1. Monk AP, Berry E, Limb D, Soames RW. Laser morphometric analysis of the glenoid fossa of the scapula. Clin Anat. 2001;14(5):320-3.

2. Solanki BS. The Angles of Scapula. J AnatSoc India.1979;28(1):16-21.

3. Lehtinen JT, Tingart MJ, Apreleva M, Warner JJP. Quantitative Morphology of the Scapula: Normal Variation of the Superomedial Scapular Angle, and Superior and Inferior Pole Thickness. Orthopedics. 2005;28(5):481-86.

4. Bardin CR. Studies of the development of human skeleton. American Journal of Anatomy. 1905;4:265-73.

5. Inman VT, Saunders JB, Dec M, Abbot LC. Observations on the functions of the shoulder joint. Journal of Bone and Joint Surgery. 1944;26:1-30.

6. Codman EA. The shoulder : Rupture of the supraspinatus tendon and other lesions in or about the anatomical bursa. Thomas Todd. Boston. Quoted by Mc Laughlin HL. Lesions of musculotendinous cuff of the shoulder. The journal of Bone and Joint Surgery. 1944;26(1):31.
7. Kelley DL. In:Kinesiology . 1st ed. New Jersey:Prentis Hall;1971.p. 47.

8. Piyawinijwong S, Sirisathira N, Chuncharunee A. The Scapula: Osseous Dimensions and Gender Dimorphism in Thais. SirirajHosp Gaz. 2004;56(7):356-65.

9. Coskun N, Karaali K, Cevikol C, Demirel BN, Sindel M. Anatomical basics and variations of the scapula in Turkish adults. Saudi Med J. 2006;27(9):1320-5.

10. Scheving LE, Pauly JE. An electromyographic study of some muscles acting on the upper extremity of man. Anatomical Record. 1959;135:239-45.

11. Basmajian JV, Bazant FJ. Factors preventing downward dislocation of the adducted shoulder joint. Journal of Bone and Joint Surgery. 1959;41-A:1186.

12. Bearn JG. An Electromyographic study of the Trapezius, Deltoid, Pectoralis major, Biceps and Triceps muscles during static loading of the upper limb. Anatomical Record. 1961;140:103-7. 